\title{
Annual Rainfall and Seasonality Predict Pan-tropical Patterns of Liana Density and Basal Area
}

\author{
Saara J. DeWalt ${ }^{1,22}$, Stefan A. Schnitzer ${ }^{2,3}$, Jérôme Chave ${ }^{4}$, Frans Bongers ${ }^{5}$, Robyn J. Burnham ${ }^{6}$, Zhiquan Cai ${ }^{7}$, Georges Chuyong ${ }^{8}$, \\ David B. Clark ${ }^{9}$, Corneille E. N. Ewango ${ }^{5,10}$, Jeffrey J. Gerwing ${ }^{11}$, Esteban Gortaire ${ }^{12}$, Terese Hart ${ }^{13}$, Guillermo Ibarra-Manríquez ${ }^{14}$, \\ Kalan Ickes ${ }^{1}$, David Kenfack ${ }^{6}$, Manuel J. Macía ${ }^{15}$, Jean-Remy Makana ${ }^{13}$, Miguel Martínez-Ramos ${ }^{14}$, Joseph Mascaro ${ }^{2}$, Sainge Moses ${ }^{16}$, \\ Helene C. Muller-Landau ${ }^{3}$, Marc P. E. Parren ${ }^{5,17}$, Narayanaswamy Parthasarathy ${ }^{18}$, Diego R. Pérez-Salicrup ${ }^{14}$, Francis E. Putz ${ }^{19}$, \\ Hugo Romero-Saltos ${ }^{12,20}$, and Duncan Thomas ${ }^{3,21}$ \\ ${ }^{1}$ Department of Biological Sciences, Clemson University, Clemson, SC 29634, U.S.A. \\ ${ }^{2}$ Department of Biological Sciences, University of Wisconsin-Milwaukee, Milwaukee, Wisconsin 53211, U.S.A. \\ ${ }^{3}$ Smithsonian Tropical Research Institute, Apartado Postal 0843-03092, Balboa, Ancon, Panamá, República de Panamá \\ ${ }^{4}$ Laboratoire Evolution et Diversité Biologique, CNRS and Université Paul Sabatier, Toulouse, France \\ ${ }^{5}$ Department of Environmental Sciences, Forest Ecology and Forest Management Group, Wageningen University, PO Box 47, 6700 AA, \\ Wageningen, The Netherlands \\ ${ }^{6}$ Department of Ecology and Evolutionary Biology, University of Michigan, Ann Arbor, MI 48109-1079, U.S.A. \\ ${ }^{7}$ Xishuangbanna Tropical Botanical Garden, Chinese Academy of Sciences, Mengla 666303, China \\ ${ }^{8}$ Department of Plant and Animal Sciences, University of Buea, PO Box 63, Buea, Southwest Province, Cameroon \\ ${ }^{9}$ Department of Biology, University of Missouri-St. Louis, MO 63121, U.S.A.; La Selva Biological Station, Costa Rica \\ ${ }^{10}$ Centre de Formation et de Recherche en Conservation Forestière, Ituri Forest, D. R. Congo \\ ${ }^{11}$ University Studies, Portland State University, Portland, Oregon 97207, U.S.A.; Instituto do Homem e Meio Ambiente da Amazônia (IMAZON), \\ Belém, Pará, Brazil \\ ${ }^{12}$ Herbario QCA, Escuela de Ciencias Biológicas, Pontificia Universidad Católica del Ecuador, Apt. 17-01-2184, Quito, Ecuador \\ ${ }^{13}$ Wildlife Conservation Society, 16 Av. Basoko, Kinshasa Gombe, D. R. Congo \\ ${ }^{14}$ Centro de Investigaciones en Ecosistemas, Universidad Nacional Autónoma de México, CP 58190 Morelia, Michoacán, Mexico \\ ${ }^{15}$ Departamento de Biología, Área de Botánica, Universidad Autónoma de Madrid, E-28049 Madrid, Spain \\ ${ }^{16}$ Korup Forest Dynamics Plot Programme, Mundemba, Southwest Province, Cameroon \\ 17 Tropenbos International Congo-Basin Programme, Yaoundé, Cameroon \\ ${ }^{18}$ Department of Ecology and Environmental Sciences, Pondicherry University, Puducherry, 605014, India \\ ${ }^{19}$ Department of Biology, University of Florida, Gainesville, Florida 32611, U.S.A. \\ 20 Department of Biology, University of Miami, Coral Gables, Florida 33124-0421, U.S.A. \\ 21 Department of Botany and Plant Pathology, Oregon State University, Corvallis, Oregon 97331, U.S.A.
}

\section{ABSTRACT}

We test the hypotheses proposed by Gentry and Schnitzer that liana density and basal area in tropical forests vary negatively with mean annual precipitation (MAP) and positively with seasonality. Previous studies correlating liana abundance with these climatic variables have produced conflicting results, warranting a new analysis of drivers of liana abundance based on a different dataset. We compiled a pan-tropical dataset containing 28,953 lianas ( $\geq 2.5 \mathrm{~cm}$ diam.) from studies conducted at 13 Neotropical and 11 Paleotropical dry to wet lowland tropical forests. The ranges in MAP and dry season length (DSL) (number of months with mean rainfall $<100 \mathrm{~mm}$ ) represented by these datasets were $860-7250 \mathrm{~mm} / \mathrm{yr}$ and $0-7 \mathrm{mo}$, respectively. Pan-tropically, liana density and basal area decreased significantly with increasing annual rainfall and increased with increasing DSL, supporting the hypotheses of Gentry and Schnitzer. Our results suggest that much of the variation in liana density and basal area in the tropics can be accounted for by the relatively simple metrics of MAP and DSL.

Abstract in Spanish is available at http://www.blackwell-synergy.com/loi/btp

Key words: abundance; climate; liana communities; tropical forest.

DETERMINING THE FACTORS THAT AFFECT THE DISTRIBUTION AND ABUNDANCE of plants is a central goal in ecology. At global scales, climatic variables such as mean annual rainfall and the seasonality of rainfall may be key predictors of vascular plant abundance, and have been hypothesized to affect directly or indirectly the density of many tropical forest plant groups (Gentry 1991, Schnitzer 2005). For example, many vascular plant life forms (e.g., trees, palms, and epiphytes) are more abundant in tropical lowland forests that receive more precipitation (Gentry 1982, 1995). In contrast, the

Received 21 April 2009; revision accepted 21 July 2009.

${ }^{22}$ Corresponding author; e-mail: saarad@clemson.edu

(C) 2009 The Author(s)

Journal compilation (C) 2010 by The Association for Tropical Biology and Conservation abundance of lianas, a key component of most tropical forests (Schnitzer \& Bongers 2002), has been hypothesized to be negatively correlated with mean annual precipitation (MAP) and positively correlated with length of the dry season (Gentry 1991, Schnitzer 2005).

Tests of these hypotheses have produced contrasting results. Schnitzer (2005) found a negative relationship between mean annual rainfall and liana density using a pan-tropical dataset collected by A. Gentry (in Phillips \& Miller 2002), as well as a negative relationship between rainfall and liana density and a positive relationship with seasonality in a study conducted across the rainfall gradient of the isthmus of Panama. In contrast, van der Heijden 
and Phillips (2008) found no relationship between mean annual rainfall and liana abundance when they used a slightly modified Neotropical subset of the Gentry dataset used by Schnitzer (2005). Furthermore, van der Heijden and Phillips (2008) also failed to find that the length of the dry season, as defined as number of consecutive months with mean rainfall $<100 \mathrm{~mm}$, was a significant predictor of liana abundance. Because lianas are important components of tropical forest structure and dynamics, and they may be increasing in abundance and biomass in lowland tropical and subtropical forests (Phillips et al. 2002, Wright et al. 2004, Wright \& Calderón 2006, Allen et al. 2007), understanding the determinants of liana abundance and biomass may provide insights into the mechanisms that govern liana communities and help explain the reported increase in liana density (Schnitzer 2005).

We tested whether liana density and basal area were related to MAP and seasonality of precipitation using a newly assembled, independent, pan-tropical dataset of lianas. We examined both liana density and basal area, which are highly correlated with estimated aboveground biomass (Schnitzer et al. 2006). Our dataset spanned a large range of liana abundance, basal area, mean annual rainfall, and seasonality of rainfall in the tropics. We used this dataset to test the hypotheses of Gentry (1991) and Schnitzer (2005) that lianas are most abundant and have higher basal area in drier tropical forests (i.e., $<2000 \mathrm{~mm} / \mathrm{yr}$ ) with greater seasonality of rainfall, and that liana abundance and basal area decrease with increasing rainfall.

\section{METHODS}

We compiled liana surveys conducted in dry to wet tropical lowland sites ( $>500 \mathrm{~mm} \mathrm{MAP} ;<1000 \mathrm{~m}$ asl; $23^{\circ} \mathrm{N}-23^{\circ} \mathrm{S}$ latitude) located in old growth forest (Fig. 1). We defined old growth forest as that which had not been cleared by humans during the last $120 \mathrm{yr}$. We included only older forests because lianas are significantly more abundant in young secondary forests ( $<$ ca $70 \mathrm{yr}$ old), whereas forests $>70 \mathrm{yr}$ old have similar liana densities to old growth forests (DeWalt et al. 2000). Additionally, we excluded oceanic islands because islands often have markedly lower liana diversity and abundance compared with nearby continental areas (Gentry 1991, Rice et al. 2004). Borneo is considered a continental-fragment island and therefore was included in the dataset. The dataset, including climate variables, was collected by this study's authors and assembled during a National Center for Ecological Analysis and Synthesis (NCEAS) liana working group.

In total, the dataset included 28,953 individual lianas $\geq 2.5$ $\mathrm{cm}$ diam. from studies conducted in 24 distinct sites (Table S1): 13 in the Neotropics (7 in South America, 5 in Central America, and 1 in Mexico) and 11 in the Paleotropics (3 in Africa, 5 in India, 2 on Borneo, and 1 in China). At several sites, multiple researchers had independently conducted liana surveys. For these sites, we averaged liana density and basal area after applying the corrections explained below.

We standardized the datasets for taxonomic groups using recommendations of Gerwing et al. (2006) and Schnitzer et al. (2008). The datasets in our analyses were modified where necessary to include only climbing woody stems that maintain connections to the ground throughout their lives. We included Smilacaceae but excluded hemiepiphytic climbers (including Araceae and Marcgraviaceae), climbing ferns, Poaceae (e.g., climbing bamboo), and Arecaceae (climbing palms). These groups were also excluded from the analysis of the Gentry Neotropical dataset conducted by van der Heijden and Phillips (2008).

Different researchers used different points of measurement (POM) of the diameter along the liana stem, which can lead to significantly different estimates of liana abundance, basal area, and biomass (Schnitzer et al. 2006). To account for tapering of liana stems with increasing distance from roots, we applied the allometric equations in Schnitzer et al. (2006) to adjust all diameter measurements to the estimated stem diameter as if measured $130 \mathrm{~cm}$ from the last substantial roots. This POM, with some exceptions when branching occurs $<130 \mathrm{~cm}$, is recommended by the NCEAS liana working group (Gerwing et al. 2006, Schnitzer et al. 2008) and was the method most commonly used in the dataset $(45 \%$ of the studies; Table S1). After adjusting diameter measurements, we included only lianas that were $\geq 2.5 \mathrm{~cm}$ diam. as measured (or estimated) at $130 \mathrm{~cm}$ from roots. We used $2.5 \mathrm{~cm}$ as a minimum diameter threshold for three reasons. First, this greater diameter allowed inclusion of most studies in our dataset. Second, this size allowed direct comparison with the dataset amassed worldwide by A. Gentry using a minimum diameter of $2.5 \mathrm{~cm}$ (Gentry 1988, Phillips \& Miller 2002), which was the basis of several studies examining the effects of climate or edaphic factors on liana density and diversity (Clinebell et al. 1995, Schnitzer 2005, van der Heijden \& Phillips 2008). Third, most lianas $>2.5 \mathrm{~cm}$ diam. are already established

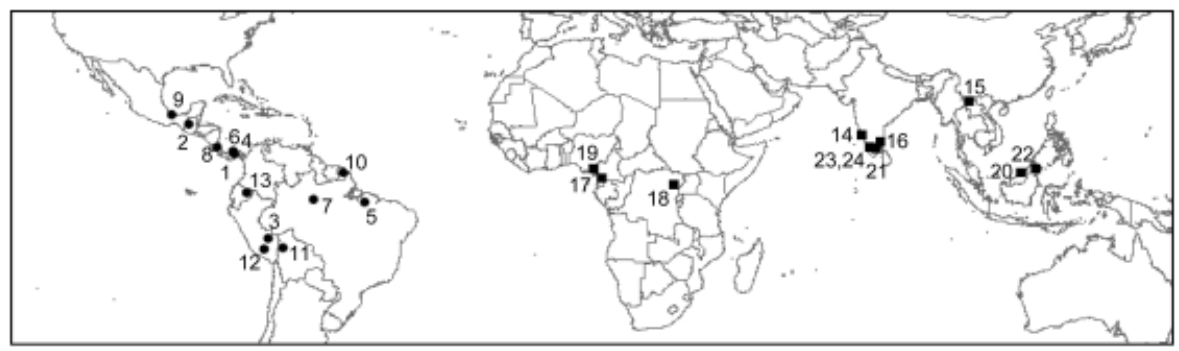

FIGURE 1. Map of sites used in this study. Numbers correspond to site codes listed in Table S1. Neotropical and Paleotropical sites are plotted with circles and squares, respectively. 
in the canopy (Kurzel et al. 2006). Therefore, these lianas have been through abiotic and biotic filters of establishment and height growth and have passed through life history stages with the highest risk of mortality.

Most of the studies (79\%) in our dataset followed lianas to determine which stems were connected aboveground or obviously connected belowground. Each group of connected stems was considered one individual liana, and the diameter measured was from the largest stem. We refer to these studies as those that sampled 'genets,' although no genetic testing was conducted to determine if nearby lianas with no stem connection were indeed genets (i.e., unique genotypes that started from seed) or separated ramets (i.e., clones whose origin is vegetative) of the same genet. Censuses at four sites did not follow lianas to determine whether stems were obviously connected to other stems, and thus counted each rooted stem as an individual. We refer to these studies as those that sampled 'ramets' (Table S1). To consider ramets as distinct individuals increases liana density substantially (Putz 1984, Schnitzer et al. 2006), and therefore we conducted analyses with and without the sites where ramets were included to determine whether the elevated density at those sites unduly influenced the relationship between climatic factors and liana density and basal area.

We did not correct for minor differences in sampling methodology between the datasets, such as whether all stems crossing a horizontal plane $130 \mathrm{~cm}$ above the ground ('crossing') or only individuals rooted within the plot ('rooted') were counted. In a study conducted in French Guiana, Schnitzer et al. (2006) found that liana density did not significantly differ when genets of rooted vs. crossing lianas were counted. Therefore, the difference in methods of using rooted vs. crossing genets probably did not affect our results. Nonetheless, we also conducted analyses on the dataset excluding sites where the crossing criterion was used.

We tested whether liana density or basal area were significantly affected by biogeographic regions (Neotropics vs. Paleotropics), by MAP, or by dry season length (DSL) using analysis of covariance (PROC GLM, Type I Sums of Squares) in SAS V. 9.1. DSL was estimated as the number of months with $<100 \mathrm{~mm} / \mathrm{mo}$. DSL has been used previously as an indicator of dry conditions (e.g., Phillips et al. 2002, van der Heijden \& Phillips 2008). Wet tropical forest transpires at least $100 \mathrm{~mm} / \mathrm{mo}$ (Hodnett et al. 1996, Malhi et al. 2002), suggesting that plants might be water limited below this amount of precipitation. Because MAP and DSL were significantly negatively correlated (Pearson's $r=-0.48, P<0.05$ ), we examined models with only region and MAP or DSL, and MAP* region or DSL* region, respectively, as predictor variables. When interaction terms were not significant, they were removed from the model and regressions were conducted including only main effects. We used the natural log of density, basal area, and MAP, but DSL was not transformed. Models using these variables provided the best curve fit and the residuals were distributed normally. We report statistics using transformed data, but figures are presented with back-transformed values. We used one-tailed probability values when examining the relationship between MAP or DSL on liana density and basal area because we tested hypotheses predicting a direction in effect (i.e., we predicted that liana density and basal area would be negatively correlated with MAP and positively correlated with DSL).

\section{RESULTS}

The 24 sites spanned a considerable range in mean annual precipitation (MAP; $860-7250 \mathrm{~mm} / \mathrm{yr}$ ) and DSL (0-7 mo). Neither MAP nor DSL differed significantly between the Neotropical and Paleotropical sites (MAP: $F_{1,22}=0.44, P=0.52$; DSL: $\left.F_{1,22}=1.27, P=0.27\right)$. A total of 106.6 ha were sampled across 24 sites. The average size sampled per site $( \pm 1 \mathrm{SD})$ was $4.4 \mathrm{ha}$ ( \pm 7.8 ); the median was 1.35 ha.

Liana density averaged $376( \pm 330)$ individuals/ha $(\geq 2.5 \mathrm{~cm}$ diam.) across the 24 sites, ranging 15-fold between 94 (Agumbe, India) and 1414 individuals/ha (Fazenda Sete, Brazil). Basal area averaged $0.71 \mathrm{~m}^{2} / \mathrm{ha}( \pm 0.46)$, ranging 12 -fold between 0.18 (Agumbe, India) and $2.1 \mathrm{~m}^{2} / \mathrm{ha}$ (Fazenda Sete, Brazil).

Consistent with the hypotheses of Gentry (1991) and Schnitzer (2005), across the tropics liana density and basal area decreased significantly with increasing precipitation and decreasing seasonality (Fig. 2), with each factor explaining 21-37 percent of the variance among sites (Table 1). Neotropical sites harbored significantly greater liana density and basal area than Paleotropical sites across MAP and DSL leading to a significant main effect of region (Fig. 3), which accounted for 19-20 percent of the variance among sites (Table 1).

The relationships between MAP and liana density and basal area were negative and of similar magnitude for both regions of the tropics (Fig. 2A, C). The two Neotropical sites with the highest liana density, Oquiriquia and Fazenda Sete, influenced the relationship between MAP and density and basal area, but the negative relationship was still statistically significant even when these sites were removed (density: $F_{1,19}=4.40, P<0.05$; basal area: $\left.F_{1,19}=5.35, P<0.05\right)$. When the four sites in the Neotropics that sampled ramets were removed from the pantropical analysis, the relationships remained significantly negative (density: $F_{1,16}=5.72$, $P<0.05$; basal area: $\left.F_{1,16}=5.89, P<0.05\right)$. When each region was examined separately, the relationship was statistically significant for density and basal area among Paleotropical sites (density: $F_{1,9}=5.07, P=0.05$; basal area: $F_{1,9}=7.00, P<0.05$ ) but not for density or basal area among Neotropical sites (density: $F_{1,11}=3.85$, $P=0.08$; basal area: $F_{1,11}=2.27, P=0.16$ ).

The relationships between DSL and liana density and basal area were positive pan-tropically (Table 1; Fig. $2 \mathrm{~B}, \mathrm{D}$ ) and were significant for both Neotropical (density: $F_{1,11}=9.55, P<0.05$; basal area: $F_{1,11}=4.96, P<0.05$ ) and Paleotropical sites (density: $F_{1,9}=7.70, P<0.05$; basal area: $\left.F_{1,9}=9.14, P<0.05\right)$. DSL remained significantly related to density $\left(F_{1,19}=9.20, P<0.01\right)$ and basal area $\left(F_{1,19}=6.93, P<0.05\right)$ when Oquiriquia and Fazenda Sete were removed. In addition, the relationship was significantly positive between DSL and density $\left(F_{1,16}=11.2, P<0.01\right)$ and basal area $\left(F_{1,16}=9.15, P<0.01\right)$ even when sites where ramets were sampled were excluded.

The residuals from all models including Neotropical and Paleotropical sites were similar in magnitude across the amount of 

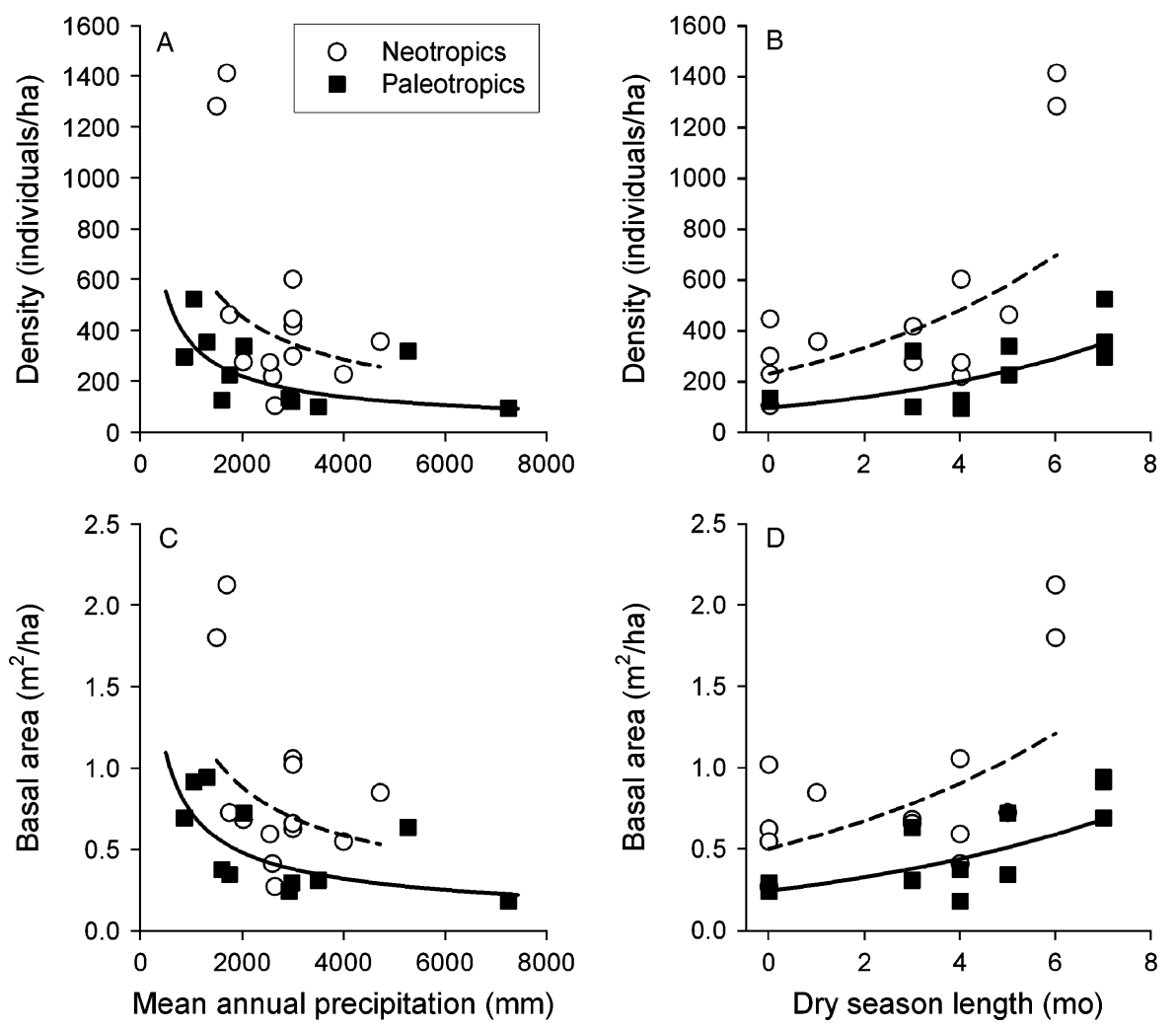

FIGURE 2. Relationships between liana density and (A) mean annual precipitation (MAP) and (B) dry season length (DSL) and between liana basal area and (C) MAP and (D) DSL. Note that higher values of DSL indicate greater seasonality. Liana density and basal area decreased significantly with MAP and increased with DSL; both liana community variables were higher across MAP and DSL for Neotropical sites (dashed line) than Paleotropical sites (solid line), leading to different y-intercepts but slopes for each regression did not differ. In (A), Neotropical density $=70,312(M A P)^{-0.663}$ and Paleotropical density $=34,201(M A P)^{-0.663}$. In $(\mathrm{B})$, Neotropical density $=230 \times \exp (1.85[D S L])$ and Paleotropical density $=96 \times \exp (1.85[D S L])$. In $(\mathrm{C})$, Neotropical basal area $=79.5(\text { MAP })^{0.592}$ and Paleotropical basal area $=43.4(M A P)^{0.592}$. In (D), Neotropical basal area $=0.503 \times \exp (0.147[D S L])$ and Paleotropical basal area $=0.245 \times \exp (0.147[D S L])$.

area sampled per site (Fig. 4). Sites that were less intensively sampled were no more likely to deviate from the predicted number of lianas or basal area than sites where greater area was sampled. In

TABLE 1. Analysis of covariance tests of effects of region (Neotropics vs. Paleotropics), mean annual precipitation (MAP) and dry season length (DSL) on liana density and basal area. None of the interaction terms were significant and were therefore removed from the model. Type I sequential sums of squares in the GLM procedure of SAS were examined for these analyses. The proportion of total sum of squares explained by region and climatic parameters are indicated for each test $\left(\mathrm{R}^{2}\right)$.

\begin{tabular}{lcccccccc}
\hline & \multicolumn{3}{c}{$\operatorname{Ln}($ Density $)$} & & \multicolumn{3}{c}{ Ln(Basal area) } \\
\cline { 2 - 3 } \cline { 7 - 9 } Source of variation & $F^{\mathrm{a}}$ & $P$ & $R^{2}$ & & $F^{\mathrm{a}}$ & $P$ & $R^{2}$ \\
\hline Region & 7.08 & 0.015 & 0.20 & & 7.04 & 0.015 & 0.19 \\
Ln(MAP) & 7.59 & 0.012 & 0.21 & & 8.68 & 0.008 & 0.24 \\
Region & 9.56 & 0.006 & 0.20 & & 8.27 & 0.009 & 0.19 \\
DSL & 17.6 & $<0.001$ & 0.37 & & 13.8 & 0.001 & 0.32 \\
\hline
\end{tabular}

${ }^{a} \mathrm{df}=1,21$ for each test. addition, area sampled did not have a significant effect on either liana variable when included as a covariate in the statistical model.

\section{DISCUSSION}

Our pan-tropical dataset supports the hypotheses that mean annual precipitation (MAP) and DSL are predictors of patterns of liana density and basal area in the tropics, with each factor explaining 21-37 percent of the variance among sites after accounting for the effect of regional differences, which explained 19-20 percent. Regardless of region, liana density and basal area both decreased in continental tropical forests with increasing rainfall and decreasing seasonality.

Our results are consistent with those of Schnitzer (2005), who found that lianas were more abundant in forests with the lowest rainfall and highest seasonality, but they contradict those of van der Heijden and Phillips (2008), who analyzed only the Neotropical sites within the same Gentry dataset used by Schnitzer (2005). MAP for the Gentry dataset ranged from 400 to $9000 \mathrm{~mm} / \mathrm{yr}$ in the Neotropics (van der Heijden \& Phillips 2008) and from 1000 to $5500 \mathrm{~mm} / \mathrm{yr}$ in the Paleotropics (Schnitzer 2005). Whereas we and Schnitzer (2005) found a significant negative relationship between 

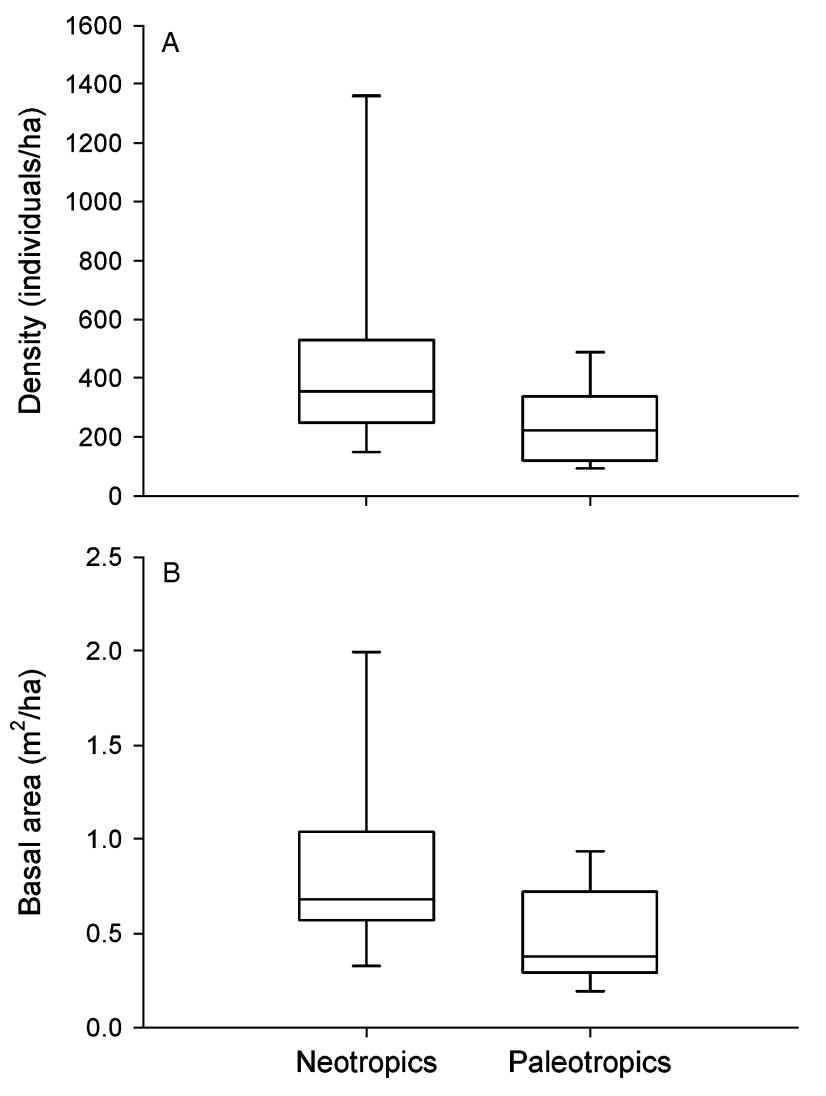

FIGURE 3. Box plots showing that Neotropical sites supported greater (A) liana density and (B) basal area than Paleotropical sites. Results of statistical tests are shown in Table 1. The 25th and 75 th percentiles are represented by the lines on the box closest and farthest from zero, and the line within the box denotes the median. Error bars below and above the box indicate the 10th and 90th percentiles, respectively.

annual rainfall and liana density, van der Heijden and Phillips (2008) found only a nonsignificant, negative trend. In addition, there was evidence in their study for a unimodal relationship between annual rainfall and liana basal area, with the highest basal area in sites of intermediate rainfall (ca $3100 \mathrm{~mm} / \mathrm{yr}$ ), whereas there was no indication of such a relationship in our dataset. They found no relationship between DSL and density, whereas we found a significant positive one. In support of our results, the site with the highest liana density in their dataset (Galerazamba, Colombia; a tropical very dry forest) received very low annual rainfall $(500 \mathrm{~mm} /$ yr) and had the highest number of dry months (11) of all their sites.

EXPLAINING DISCREPANCIES AMONG STUDIES.-There are several possible explanations for the discrepancy between the results of van der Heijden and Phillips (2008) and our study. First, as van der Heijden and Phillips (2008) suggested to explain the difference between their study and that of Schnitzer (2005), the relationship between MAP and liana density and basal area may vary regionally, with a stronger pattern in the Paleotropics. Indeed, when we examined our data by region, we found a significant negative relationship

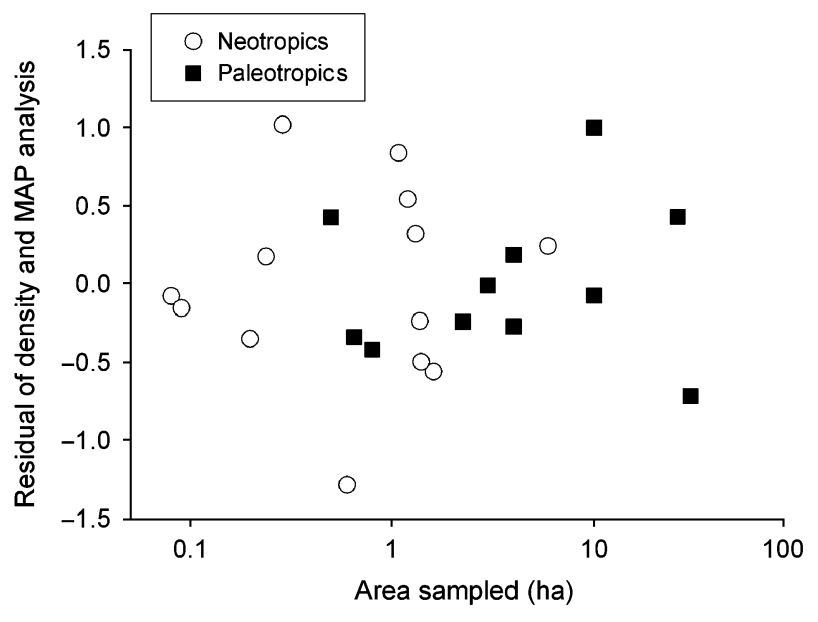

FIGURE 4. Plot of the area sampled against the residuals of the model examining how density was related to mean annual precipitation (MAP). The magnitude of the residuals did not change over area sampled.

between MAP and liana density and basal area for Paleotropical sites but not for Neotropical sites. However, the slope of the relationship did not differ significantly between regions, suggesting that liana density and basal area follow similar patterns with MAP in the Neotropics. The lack of a significant relationship in the Neotropics but not Paleotropics when examining the regions separately likely resulted from the smaller range of precipitation sampled in the Neotropics $(1500-4725 \mathrm{~mm} / \mathrm{yr}$ ) than in the Paleotropics $(860-7250 \mathrm{~mm} / \mathrm{yr})$, and therefore failed to capture high MAP where liana density would be lowest. In fact, when we analyzed the Paleotropical sites in our dataset within the MAP range of our Neotropical sites, the relationship between MAP and liana density and basal area were not significant. In addition, the relationship between liana density and basal area and DSL was significantly positive for both Neotropical and Paleotropical sites when examined separately. Thus, it appears the pattern between climatic variables and liana success is not necessarily stronger in the Paleotropics than Neotropics, negating that explanation for why the two datasets yield different results.

Second, the discrepancy between datasets could arise from differences in the range of climatic variation among the sites included in the two datasets. Our dataset did not include any forests with MAP $<860 \mathrm{~mm} / \mathrm{yr}$, whereas the Gentry dataset included four such sites, with one as low as $400 \mathrm{~mm} / \mathrm{yr}$ (Yanaigua, Bolivia; a tropical thorn woodland). However, when we analyzed the Gentry data reported in Supplement 1 of van der Heijden and Phillips (2008) and excluded sites $>1000 \mathrm{~m}$ in elevation and with MAP $<860$, to make the dataset more analogous to our own, there was still no significant relationship between MAP and liana density. Thus, differences in climatic range variation do not explain the disparity between our study and that of van der Heijden and Phillips (2008).

A third possible explanation for the discrepancy between the two studies is that the 65 sites analyzed by van der Heijden and 
Phillips (2008) each represented such a small area that each site provided an imprecise estimate of forest-level liana abundance and basal area. Although Gentry sampled across an area of several hectares in each site with 10 transects each of $2 \times 50 \mathrm{~m}$ scattered across the landscape, the total area sampled for each site $(0.1 \mathrm{ha})$ was much smaller than all but two of our sites (Cocoli and Fort Sherman, Panama). Sampling a greater area captures more of the forest spatial heterogeneity, including both gap (often with relatively high liana densities) and closed-forest sites (often with relatively low liana densities). Most of our Neotropical sites sampled much greater areas $($ mean $=1.18$ ha; median $=1.35 \mathrm{ha})$ in wider transects or plots than Gentry's, and therefore likely provided more precise estimates of liana abundance and basal area. We suggest that the high sampling error likely associated with estimations of liana density and basal area in Gentry's small plots may hinder detection of underlying regional or global patterns using his dataset. To aid future intersite comparisons of liana density and basal area, we encourage the use of the standard protocols for censusing lianas proposed by Gerwing et al. (2006) and Schnitzer et al. (2008) as well as sampling areas $>0.1$ ha.

EXPLAINING INCREASING LIANA DENSITY AND BASAL AREA WITH DECREASING RAINFALL AND INCREASING SEASONALITY.-If liana establishment and growth are favored by low rainfall and high seasonality leading to greater abundance and basal area under these conditions, what is the mechanism? One possibility is that understory light levels are higher in drier tropical forests throughout the year than in wet forests, regardless of seasonality (Condit et al. 2000). Light is thought to be one of the most important factors determining liana proliferation (Putz 1984, Schnitzer et al. 2000), and thus higher yearround light or increases in light when trees become deciduous in the dry season would favor lianas in drier and more seasonal forests. Kurzel et al. (2006) suggested that the relatively high amount of light penetrating into drier forests may increase liana germination, growth, and survival in the understory, which in turn may increase liana performance and thus abundance in drier forests. Indeed, lianas are often found in greater relative abundance in high-light areas, such as forest edges and treefall gaps, than in the intact forest understory (Putz 1984, Schnitzer et al. 2000, Laurance et al. 2001). Lianas also proliferate in the high-light conditions following land abandonment and decline in abundance, both as seedlings and adults, as understory light levels decrease over tropical forest succession (DeWalt et al. 2000, Capers et al. 2005).

Although lianas may be favored by higher light in sites with lower rainfall and higher seasonality, they must also cope with drought, which occurs more often in forests with lower annual rainfall and longer dry seasons. Schnitzer (2005) summarized the morphological traits that may confer a growth advantage to lianas during the dry season. For example, several liana species have been found to have relatively deep roots (Tyree \& Ewers 1996, Restom \& Nepstad 2004, Andrade et al. 2005) and high water-use efficiency (Cai et al. 2009b). These traits may allow lianas to keep a substantial number of their leaves and grow during seasonal droughts when many competing trees are deciduous, and thereby confer a competitive advantage to lianas in drier or more seasonal tropical forests. In the seasonal forest of Barro Colorado Island, Panama, Schnitzer (2005) found that lianas grew seven times faster than trees in the dry season but only twice as fast in the wet season. In southwestern China, Cai et al. (2009b) found that lianas maintained relatively high rates of photosynthesis during the dry season, whereas photosynthesis in co-occurring trees dropped significantly during that time. Thus, the ability to grow during the dry season, when competing growth forms are mostly dormant, may explain why lianas are more abundant in forests with less MAP and greater DSL.

DSL and MAP may also affect the size-class distribution of trees, which could indirectly affect the liana community. If drier tropical forests have a greater density of small trees, which are more suitable hosts for lianas of all twining types (Putz 1984, Putz \& Holbrook 1991), then drier forests may support more lianas than wetter forests. The abundance of small trees clearly varies among tropical forest plots, and its relationship to MAP and DSL is complicated (Muller-Landau et al. 2006). Pairing liana and tree surveys would help to address the relationships between climate, host availability, and liana density and basal area.

We found a strong positive relationship between DSL and liana density and basal area, but DSL, defined as the number of calendar months with long-term mean rainfall $\leq 100 \mathrm{~mm} / \mathrm{yr}$, may be a poor proxy for soil water availability. The beginning and end of calendar-months are artificial endpoints, and months vary in length, such that the same rainfall regime (i.e., same average rain per day for $365 \mathrm{~d}$ in sequence) could produce different DSL simply by shifting which day corresponds to 1 January. In addition, plants growing in sites with similar dry season lengths but on soils differing in water-holding capacity do not experience the same levels of drought stress (Engelbrecht et al. 2007) because plants on low water holding-capacity soils experience drought conditions more quickly. Thus, the same DSL value in different sites may affect plants to different degrees depending on local site conditions (e.g., topography, soils, winds) and distribution of rainfall during the year. Nonetheless, our results suggest that seasonality of rainfall, even if measured with DSL, is an important climatic variable needed to understand the global distribution of lianas.

Does MAP or DSL have a greater effect on liana abundance and basal area in the tropics? Models with DSL explained more of the variance (i.e., had higher $R^{2}$ ) than those with MAP, suggesting that DSL may be a better predictor of liana density and basal area. Indeed, even with the limitations pointed out above, DSL may better reflect the degree to which plants experience water stress. Most tropical forests have sufficient water during the wet season, so more or less rainfall during the wet season likely will not affect water availability (i.e., MAP can vary without changing plant water stress). However, the length of the dry season directly determines the duration of water limitation. Because MAP and DSL were highly correlated in our study, we would need more sites with high rainfall and high seasonality, i.e., $>2000 \mathrm{~mm} / \mathrm{yr}$ and $>4$ consecutive dry months (e.g., tropical monsoon forests) to separate their relative effects. In our dataset, only the Ebom site in Cameroon experiences high rainfall and high seasonality $(2035 \mathrm{~mm} / \mathrm{yr}$ and 5 dry mo during two dry seasons). Adding liana surveys in tropical forests 
that receive both high rainfall and high seasonality may help determine which factor has a greater effect on liana abundance and basal area.

BIOGEOGRAPHICAL PATTERNS IN LIANA DISTRIBUTION.- In our study, Neotropical forests harbored more lianas than Paleotropical forests, yet we do not believe that our data are robust enough to definitively claim that lianas are systematically more abundant in Neotropical forests than in Paleotropical forests. Our samples in the Neotropics were from a drier subset of the rainfall spectrum $(1500-4725 \mathrm{~mm} /$ yr) than our samples in the Paleotropics $(860-7250 \mathrm{~mm} / \mathrm{yr})$. Thus, in the Neotropics, we lacked very wet sites, such as the Choco area of Colombia, which would be predicted to have very low liana density and basal area. To compare liana abundance and basal area among biogeographical regions properly, more liana surveys need to be conducted across the Americas, Asia, and Africa with enough sites to represent the full range in climatic conditions present in each region (for such a comparison of tree diversity between Amazonia and Africa see Parmentier et al. 2007).

CONCLUSION.-We tested the relationship between MAP and DSL using the largest available dataset in terms of area sampled and found strong support for the hypotheses that liana density and basal area decrease with increasing rainfall and increase with increasing seasonality of rainfall. The number of sites included in our study (24) was relatively small compared with the Gentry dataset (Phillips \& Miller 2002), but our study sites spanned a large range of rainfall and seasonality and represented all continents with tropical forest, with the exception of Australia. Our results suggest that lianas are most successful in drier tropical forests. Unexplained variation in liana abundance and basal area among sites may be attributed to other environmental factors such as differences in soils, drainage, and topography (Proctor et al. 1983, Putz \& Chai 1987, Gentry 1991, Laurance et al. 2001, Ibarra-Manríquez \& Martínez-Ramos 2002, DeWalt \& Chave 2004, DeWalt et al. 2006); availability of suitable hosts (trellises) caused by differences in tree composition or size (Putz 1984, Balfour \& Bond 1993, Campbell \& Newbery 1993); rates and extents of large-scale disturbances, such as hurricanes (Quigley \& Platt 2003, Rice et al. 2004, Garrido-Pérez et al. 2008); rates and extents of small-scale disturbances, such as treefall gaps (Putz 1984, Putz \& Chai 1987, Schnitzer et al. 2000, Schnitzer \& Carson 2001); and sampling error. Nonetheless, it appears that the liana density and basal area in a particular tropical site are strongly related to the relatively simple metrics of MAP and DSL.

\section{ACKNOWLEDGMENTS}

This work was conducted as a part of the Lianas and Tropical Forest Dynamics Working Group supported by the NCEAS, a Center funded by NSF (Grant \#EF-0553768), the University of California, Santa Barbara, and the State of California. Data collection and management were funded by many organizations including the HSBC Climate Partnership, NSF, National Science Foundation of China, Wageningen University, Department of Science and Tech- nology of the Government of India, World Wildlife Fund (Brazil), USAID, Organization for Tropical Studies, British Ecological Society, CONACyT (Mexico), European Commission, Fondo Mexicano para la Conservación de la Naturaleza, BOLFOR, PAPIITUNAM, Center for Tropical Forest Science, Smithsonian Tropical Research Institute, University of Wisconsin-Milwaukee Graduate School, International Cooperative Biodiversity Groups, Bioresources Development and Conservation Programme-Cameroon, Ministry of Environment and Forests-Cameroon, Centre National de la Recherche Scientifique, UNESCO, University of Miami, Pontificia Universidad Católica del Ecuador, REPSOL-YPF, and the Andrew W. Mellon Foundation. D. Zoellner helped create the map of study sites. We appreciate comments on the manuscript by M. Peña-Claros, G. van der Heijden, and an anonymous reviewer and discussions with L. Poorter.

\section{SUPPORTING INFORMATION}

Additional Supporting Information may be found in the online version of this article:

TABLE S1. Characteristics of sites and methods used in liana studies at each site. Density is mean number of lianas per ha. BA is basal area $\left(\mathrm{m}^{2} / \mathrm{ha}\right.$ ). Alt. is mean altitude ( $\mathrm{m}$ asl) of plots within each site. MAP is mean annual precipitation ( $\mathrm{mm} / \mathrm{yr})$. DSL is the number of months of dry season $(<100 \mathrm{~mm} / \mathrm{mo})$. Area sampled is total number of ha sampled across studies at each site. G/R denotes whether only one individual per apparent genet $(\mathrm{G})$ or all ramets $(\mathrm{R})$ were enumerated in each study. POM is the point of diameter measurement for each study (20 $=20 \mathrm{~cm}$ from roots; $130 \mathrm{R}=130 \mathrm{~cm}$ from roots; $130 \mathrm{G}=130 \mathrm{~cm}$ perpendicular from ground; $\mathrm{L}=$ largest point devoid of stem abnormalities). $\mathrm{C} / \mathrm{R}$ denotes whether all lianas crossing a plane at $130 \mathrm{~cm}$ above the ground (C) or only lianas rooted within the plot (R) were enumerated. Source denotes the citation for each study. For references, see main manuscript text.

Please note: Wiley-Blackwell are not responsible for the content or functionality of any supporting materials supplied by the authors. Any queries (other than missing material) should be directed to the corresponding author for the article.

\section{LITERATURE CITED}

Allen, B. P., R. R. Sharitz, and P. C. Goebel. 2007. Are lianas increasing in importance in temperate floodplain forests in the southeastern United States? For. Ecol. Manage. 242: 17-23.

Andrade, J. L., F. C. Meinzer, G. Goldstein, and S. A. Schnitzer. 2005. Water uptake and transport in lianas and co-occurring trees of a seasonally dry tropical forest. Trees 19: 282-289.

Balfour, D. A., AND W. J. Bond. 1993. Factors limiting climber distribution and abundance in a southern African forest. J. Ecol. 81: 93-99.

Bongers, R., J. Popma, J. Meave del Castillo, and J. Carabias. 1988. Structure and floristic composition of the lowland rain forest of Los Tuxtlas, Mexico. Vegetatio 74: 55-80.

Burnham, R. J. 2002. Dominance, diversity and distribution of lianas in Yasuní, Ecuador: Who is on top? J. Trop. Ecol. 18: 845-864. 
Cai, Z.-Q., Y. J. Chen, B. Wen, S. A. SChNitZer, AND F. Bongers. 2009a. Liana diversity and abundance in three tropical forests in Xishuangbanna, SW China. J. Trop. For. Sci. 21: 252-264.

Cai, Z.-Q., S. A. SCHNitzer, AND F. BONGERs. 2009b. Seasonal differences in leaf-level physiology give lianas a competitive advantage over trees in a tropical seasonal forest. Oecologia 161: 25-33.

Campbell, E. J. F., AND D. M. Newbery. 1993. Ecological relationships between lianas and trees in lowland rain forest in Sabah, East Malaysia. J. Trop. Ecol. 9: 469-490.

Capers, R. S., R. L. Chazdon, A. R. Brenes, and B. V. Alvarado. 2005. Successional dynamics of woody seedling communities in wet tropical secondary forests. J. Ecol. 93: 1071-1084.

Clingbell, R. R. II, O. L. Phillips, A. H. Gentry, N. Stark, and H. Zuuring. 1995. Prediction of Neotropical tree and liana species richness from soil and climatic data. Biodiv. Conserv. 4: 56-90.

Condit, R., K. Watts, S. A. Bohlman, R. Perez, R. B. Foster, and S. P. HubBELL. 2000. Quantifying the deciduousness of tropical forest canopies under varying climates. J. Veg. Sci. 11: 649-658.

DeWalt, S. J., and J. Chave. 2004. Structure and biomass of four lowland Neotropical forests. Biotropica 36: 7-19.

DeWalt, S. J., K. Ickes, R. Nilus, K. E. Harms, and D. F. R. P. Burslem. 2006. Liana habitat associations and community structure in a Bornean lowland tropical forest. Plant Ecol. 186: 203-216.

DeWalt, S. J., S. A. Schnitzer, and J. S. Denslow. 2000. Density and diversity of lianas along a chronosequence in a central Panamanian tropical forest. J. Trop. Ecol. 16: 1-19.

Engelbrecht, B. M. J., L. S. Comita, R. Condit, T. A. Kursar, M. T. Tyree, B. L. TuRner, AND S. P. HubBell. 2007. Drought sensitivity shapes species distribution patterns in tropical forests. Nature 447: 80-82.

Garrido-Pérez, E. I., J. M. Dupuy, R. Durán-García, M. Ucan-May, S. A. Schnitzer, AND G. Gerold. 2008. Effects of lianas and Hurricane Wilma on tree damage in the Yucatan Peninsula, Mexico. J. Trop. Ecol. 24: 559-562.

Gentry, A. H. 1982. Patterns of Neotropical plant species diversity. Evol. Biol. 15: $1-84$.

Gentry, A. H. 1988. Changes in plant community diversity and floristic composition on environmental and geographical gradients. Ann. Mo. Bot. Gard. 75: 1-34.

Gentry, A. H. 1991. The distribution and evolution of climbing plants. In F. E. Putz and H. A. Mooney (Eds.). The biology of vines, pp. 3-49. Cambridge University Press, Cambridge, UK.

Gentry, A. H. 1995. Diversity and floristic composition of Neotropical dry forests. In S. H. Bullock, H. A. Mooney, and E. Medina (Eds.). Seasonally dry tropical forests, pp. 146-194. Cambridge University Press, Cambridge, UK.

Gerwing, J. J., S. A. Schnitzer, R. J. Burnham, F. Bongers, J. Chave, S. J. DeWalt, C. E. N. Ewango, R. Foster, D. Kenfack, M. MartínezRamos, M. Parren, N. Parthasarathy, D. R. Pérez-Salicrup, F. E. PutZ, AND D. W. Thomas. 2006. A standard protocol for liana censuses. Biotropica 38: 256-261.

Hodnett, M. G., M. D. Oyama, J. Tomasella, and A. de O. Marques Filho. 1996. Comparisons of long-term water storage behaviour under pasture and forest in three regions of Amazonia. In J. H. C. Gash, C. A. Nobre, J. M. Roberts, and R. L. Victoria (Eds.). Amazonian deforestation and climate, pp. 55-77. Wiley, New York, New York.

Ibarra-Manríquez, G., and M. Martínez-Ramos. 2002. Landscape variation of liana communities in a Neotropical rain forest. Plant Ecol. 160: 91-112.

Kurzel, B. P., S. A. Schnitzer, and W. P. Carson. 2006. Predicting liana crown location from stem diameter in three Panamanian lowland forests. Biotropica 38: 262-266.

Laurance, W. F., D. Pérez-Salicrup, P. Delamônica, P. M. Fearnside, S. D’Angelo, A. Jerozolinski, L. Pohl, and T. E. Lovejoy. 2001. Rain forest fragmentation and the structure of Amazonian liana communities. Ecology 82: 105-116.
Malhi, Y., E. Pegoraro, A. D. Nobre, M. G. P. Pereira, J. Grace, A. D. Culf, And R. Clement. 2002. The water and energy dynamics of a central Amazonian rain forest. J. Geophys. Res. Atmosph. 107 (D20): 8061, doi: 10.1029/2001JD000623.

Mascaro, J., S. A. Schnitzer, AND W. P. Carson. 2004. Liana diversity, abundance, and mortality in a tropical wet forest in Costa Rica. For. Ecol. Manage. 19: 3-14.

Muller-Landau, H. C., R. S. Condit, K. E. Harms, C. O. Marks, S. C. Thomas, S. Bunyavejchewin, G. Chuyong, L. Co, S. Davies, R. Foster, S. Gunatilleke, N. Gunatilleke, T. Hart, S. P. Hubbell, A. Itoh, A. R. Kassim, D. Kenfack, J. V. LaFrankie, D. Lagunzad, H. S. Lee, E. Losos, J.-R. Makana, T. Ohkubo, C. Samper, R. Sukumar, I. F. Sun, M. N. Nur Supardi, S. Tan, D. Thomas, J. Thompson, R. Valencia, M. I. Vallejo, G. V. Munoz, T. Yamakura, J. K. Zimmerman, and H. S. Dattaraja. 2006. Comparing tropical forest tree size distributions with the predictions of metabolic ecology and equilibrium models. Ecol. Lett. 9: 589-602.

Muthuramkumar, S., N. Ayyappan, N. Parthasarathy, D. Mudappa, T. R. S. Raman, M. A. Selwyn, and L. A. Pragasan. 2006. Plant community structure in tropical rain forest fragments of the Western Ghats, India. Biotropica 38: 143-160.

Muthuramkumar, S., and N. Parthasarathy. 2000. Alpha diversity of lianas in a tropical evergreen forest in the Anamalais, Western Ghats, India. Div. Distrib. 6: 1-14.

Padaki, A., AND N. Parthasarathy. 2000. Abundance and distribution of lianas in tropical lowland evergreen forest of Agumbe, central Western Ghats, India. Trop. Ecol. 41: 143-154.

Parmentier, I., Y. Malhi, B. Senterre, R. J. Whittaker, A. T. D. N. Alonso, A, M. P. B. Balinga, A. Bakayoko, F. Bongers, C. Chatelain, J. A. Comiskey, R. Cortay, M.-N. Djuikouo Kamdem, J.-L. Doucet, L. Gautier, W. D. Hawthorne, Y. A. Issembe, F. N. Kouamé, L. A. Kouka, M. E. Leal, J. Lejoly, S. L. Lewis, L. Nusbaumer, M. P. E. Parren, K. S.-H. Peh, O. L. Phillips, D. Sheil, B. Sonké, M. S. M. Sosef, T. C. H. Sunderland, J. Stropp, H. T. Steege, M. D. Swaine, M. G. P. Tchouto, B. S. Van Gemerden, J. L. C. H. Van Valkenburg, and H. WÖLL. 2007. The odd man out? Might climate explain the lower tree $\alpha$-diversity of African rain forests relative to Amazonian rain forests? J. Ecol. 95: 1058-1071.

Parren, M. P. E. 2003. Lianas and logging in West Africa. PhD Dissertation. Wageningen University, Tropenbos-Cameroon Series 6. Tropenbos International, Wageningen, The Netherlands.

Pérez-Salicrup, D. R., V. L. Sork, and F. E. Putz. 2001. Lianas and trees in a liana forest of Amazonian Bolivia. Biotropica 33: 34-47.

Phillips, O. L., AND J. Miller. 2002. Global patterns of plant diversity: Alwyn H. Gentry's forest transect data set. Missouri Botanical Garden, St. Louis, Missouri.

Phillips, O. L., M. R. VÁsquez, L. Arroyo, T. B. Baker, T. Killeen, S. L. Lewis, Y. Malhi, A. Monteagudo Mendoza, D. Neill, P. Nuñez V, M. Alexiades, C. Cerón, A. Di Fiore, T. Erwin, A. Jardim, W. PalaCIOS, M. SALDIAS, AND B. VINCETI. 2002. Increasing dominance of large lianas in Amazonian forests. Nature 418: 770-774.

Proctor, J., J. M. Anderson, P. Chai, and H. W. Vallack. 1983. Ecological studies in four contrasting lowland rain forests in Gunung Mulu National Park, Sarawak I. Forest environment, structure, and floristics. J. Ecol. 71: 237-260.

PutZ, F. E. 1984. The natural history of lianas on Barro Colorado Island, Panama. Ecology 65: 1713-1724.

PutZ, F. E., AND P. Chai. 1987. Ecological studies of lianas in Lambir National Park, Sarawak, Malaysia. J. Ecol. 75: 523-531.

PutZ, F. E., AND N. M. Holbrook. 1991. Biomechanical studies of vines. In F. E. Putz and H. A. Mooney (Eds.). The biology of vines, pp. 73-97. Cambridge University Press, Cambridge, UK.

Quigley, M. F., and W. J. Platt. 2003. Composition and structure of seasonally deciduous forests in the Americas. Ecol. Monogr. 73: $87-106$. 
Reddy, M. S., AND N. Parthasarathy. 2003. Liana diversity and distribution in four tropical dry evergreen forests on the Coromandel coast of south India. Biodiv. Conserv. 12: 1609-1627.

Reddy, M. S., and N. Parthasarathy. 2006. Liana diversity and distribution on host trees in four inland tropical dry evergreen forests of peninsular India. Trop. Ecol. 47: 109-123.

Restom, T. G., and D. C. Nepstad. 2004. Seedling growth dynamics of a deeply rooting liana in a secondary forest in eastern Amazonia. For. Ecol. Manage. 190: 109-118.

Rice, K., N. Brokaw, and J. Thompson. 2004. Liana abundance in a Puerto Rican forest. For. Ecol. Manage. 190: 33-41.

Romero-Saltos, H., R. Valencia, and M. J. Macía. 2001. Patrones de diversidad, distribución y rareza de plantas leñosas en el Parque Nacional Yasuní y la Reserva Étnica Huaorani, Amazonía ecuatoriana. In J. F. Duivenvoorden, H. Balslev, J. Cavelier, C. Grández, H. Tuomisto, and R. Valencia (Eds.). Evaluación de productos forestales no maderables en la Amazonía noroccidental, pp. 131-162. IBED, Universiteit van Amsterdam, Amsterdam, The Netherlands.

SCHNITZER, S. A. 2005. A mechanistic explanation for global patterns of liana abundance and distribution. Am. Nat. 166: 262-276.

SChnitzer, S. A., AND F. Bongers. 2002. The ecology of lianas and their role in forests. Trends Ecol. Evol. 17: 223-230.
SCHNITZER, S. A., AND W. P. CARSON. 2001. Treefall gaps and the maintenance of species diversity in a tropical forest. Ecology 82: 913-919.

Schnitzer, S. A., J. W. Dalling, and W. P. Carson. 2000. The impact of lianas on tree regeneration in tropical forest canopy gaps: Evidence for an alternative pathway of gap-phase regeneration. J. Ecol. 88: 655-666.

Schnitzer, S. A., S. J. DeWalt, and J. Chave. 2006. Censusing and measuring lianas: A quantitative comparison of the common methods. Biotropica 38: 581-591.

Schnitzer, S. A., S. Rutishauser, and S. Aguilar. 2008. Supplemental protocol for censusing lianas. For. Ecol. Manage. 255: 1044-1049.

Tyree, M. T., AND F. W. Ewers. 1996. Hydraulic architecture of woody tropical plants. In S. S. Mulkey, R. L. Chazdon, and A. P. Smith (Eds.). Tropical forest plant ecophysiology, pp. 217-243. Chapman and Hall, New York, New York.

van der Heijden, G. M. F., And O. L. Phillips. 2008. What controls liana success in Neotropical forests? Glob. Ecol. Biogeogr. 17: 372-383.

Wright, S. J., ANd O. Calderón. 2006. Seasonal, el Niño and longer term changes in flower and seed production in a moist tropical forest. Ecol. Lett. 9: 35-44.

Wright, S. J., O. Calderón, A. Hernandéz, and S. Paton. 2004. Are lianas increasing in importance in tropical forests? A 17-year record from Panamá. Ecology 85: 484-489. 